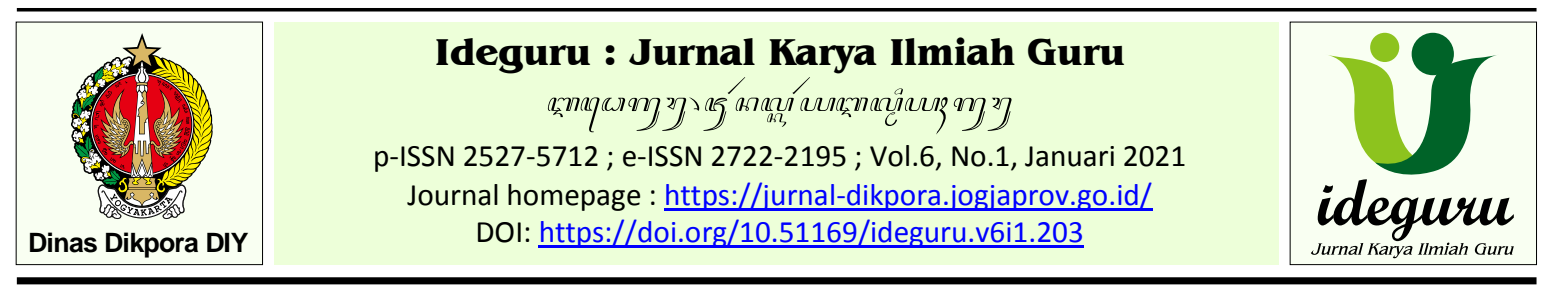

Best Practice - Naskah dikirim: 11/01/2021 - Selesai revisi: 08/03/2021 - Disetujui: 10/03/2021 - Diterbitkan: 15/03/2021

\title{
Modifikasi Laminar sebagai Alat Pembelajaran Biologi SMA Materi Mikroorganisme
}

\author{
Ariswati Baruno \\ SMA Negeri 7 Yogyakarta \\ ariswati99@gmail.com
}

\begin{abstract}
ABSTRAK: Pada umumnya, untuk memperoleh ruang kerja steril digunakan laminar air flow, namun karena harganya relatif mahal menjadikan tidak terbeli. Oleh karena itu, dilakukan inovasi untuk membuat laminar modifikasi (Lamodis). Tujuan pembuatan lamodis adalah dapat memberikan ruang kerja steril dengan harga lebih murah daripada laminar pada umumnya karena tingkat keberhasilan yang tinggi atas praktikum didukung oleh ruang kerja yang steril. Penulisan best practise ini bertujuan untuk mengatasi kegagalan praktikum Biologi pada materi yang terkait dengan mikroorganisme agar siswa mendapatkan pemahaman yang lebih baik akan materi dan meningkatkan keterampilan di setiap langkah dalam melakukan praktikum terkait mikrorganisme dengan menggunakan lamodis. Pembuatan Lamodis menggunakan bahan-bahan yang ada di sekitar namun tetap mengaplikasikan prinsip dasar pembuatan. Uji kontaminasi media yang dituang di dalam dan di luar Lamodis menunjukkan bahwa uji di dalam Lamodis memiliki persentase tidak terkontaminasi sebesar 83,5\%, yang lebih baik daripada di luar Lamodis yang sebesar 79\%. Hasil rerata nilai angket terhadap siswa adalah 3,31 dari maksimal 4,00 yang menunjukkan bahwa Lamodis cukup baik untuk digunakan untuk sterilisasi. Penggunaan Lamodis meningkatkan keterampilan siswa dalam melakukan prosedur aseptik. Karenanya pembuatan Lamodis mendukung pembelajaran Biologi SMA yang terkait dengan mikroorganisme.
\end{abstract}

Kata kunci: Lamodis, pembelajaran biologi SMA, mikroorganisme, steril.

\section{Laminar Modification as Senior High School Learning Apparatus on Microorganism Subject}

ABSTRACT: Commonly, laminar air flow used to provide a sterile workplace, however, it could not bought because its price was expensive enough. Therefore, Laminar Modification (Lamodis) innovation was made. The purpose of Lamodis is to provide a sterile workplace with more affordable laminar because the high rate of success of a lab practice needs to be supported by a sterile workplace. The purpose of the best practice is to resolve biology lab practice failure cases related to the microorganism, with the aim that the students can access a better understanding of the material and improve their skills in every step when working on lab practice relate to microorganism. Lamodis were made with materials that can easily found but still applying the basic principle of the manufacture. The contamination test of media poured inside and outside Lamodis showed that the test inside Lamodis had a non-contaminated percentage of $83.5 \%$, which was better than outside Lamodis which was 79\%. The mean result of the questionnaire value for students was 3.31 from a maximum of 4.00 which indicated that Lamodis was good enough to be used for sterilization. The use of Lamodis improves students' skills in performing aseptic procedures. Therefore, the Lamodis made supports high school biology learning related to microorganisms.

Keywords: Lamodis, senior high school biology learning, microorganism, sterilization.

\section{Pendahuluan}

Kurikulum 2013 yang telah diterapkan bertahun-tahun di beberapa sekolah di Indonesia, termasuk di Daerah Istimewa Yogyakarta, menempatkan siswa sebagai pembelajar yang mandiri. Peserta didik sudah bukan menjadi obyek belajar lagi, melainkan merupakan subyek belajar. Peserta didik diharapkan mampu menemukan dan mengembangkan sendiri topiktopik pembelajaran yang diberikan. Peserta didik dituntut untuk berpikir kritis, kreatif, mampu berkolaborasi, serta dapat mengkomunikasikan baik pendapat maupun hasil penelitian. Sedangkan guru, dalam hal ini berperan sebagai fasilitator agar peserta didik dapat memiliki kecakapan sesuai dengan tujuan kurikulum. 
Salah satu cara agar guru dapat memfasilitasi berkembangnya pemikiran peserta didik adalah dengan menerapkan model pembelajaran yang sesuai. Salah satu model pembelajaran yang dapat digunakan adalah scientific inquiry. Model pembelajaran ini menerapkan kaidah metode ilmiah. Penerapan kaidah metode ilmiah dimaksudkan agar peserta didik menemukan dan memahami permasalahan yang sedang dikaji.

Mata pelajaran sains, khususnya biologi, sangat sesuai diajarkan dengan model scientific inquiry. Akan tetapi, terkadang guru menemui kesulitan dalam mengimplementasikan model pembelajaran ini karena adanya keterbatasan sarana prasarana di sekolah. Sebagai contoh, pada kelas X terdapat materi tentang bakteri dan kelas XII terdapat materi bioteknologi. Rumusan kompetensi dasar pada kompetensi keterampilan untuk materi bakteri kelas $\mathrm{X}$ memuat tujuan peserta didik dapat menyajikan ciri-ciri bakteri. Agar peserta didik dapat menyajikan ciri-ciri bakteri, akan lebih baik apabila peserta didik dapat mengamati langsung bagaimana bentuk berbagai macam bakteri. Hal ini membutuhkan adanya praktikum terkait inokulasi bakteri dan pengamatan bakteri. Sementara itu, pada kompetensi keterampilan materi bioteknologi kelas XII dirumuskan bahwa peserta didik diharapkan dapat menyajikan laporan hasil percobaan penerapan prinsip bioteknologi konvensional. Hal ini menuntut dilakukannya percobaan penerapan prinsip bioteknologi konvensional. Kedua materi tersebut membutuhkan kondisi steril dan aseptis untuk praktikum.

Kondisi lingkungan yang tidak steril tersebut disebabkan karena praktikum dilakukan di meja praktikum, dalam ruang laboratorium yang tidak dapat dikendalikan kondisi aseptiknya, dilakukan penyemprotan alkohol di sekeliling meja praktikum, dan aktivitas dilakukan di depan lampu spiritus. Karena luasnya ruang laboratorium, maka penyemprotan alkohol pada area terbatas menjadi kurang efektif untuk mengendalikan mikroorganisme lain dalam ruang laboratorium.

Pembelajaran biologi di Sekolah Menengah Atas Negeri (SMAN) 7 Yogyakarta sudah sejak lama berupaya memberikan pengalaman belajar yang menerapkan scientific inquiry terhadap peserta didik. Akan tetapi, guru mengalami kesulitan dalam mengajarkan tentang materi yang terkait dengan teknik aseptik, seperti materi mikrobiologi, jamur, dan bioteknologi konvensional. Hasil praktikum yang dilakukan sering kurang memuaskan karena terkontaminasi mikroorganisme yang tidak diinginkan. Upaya membatasi area kerja steril telah dicoba dengan menggunakan akuarium, namun selain masih terjadi kontaminasi, beberapa kendala teknis tidak memungkinkan pemakaian akuarium lebih lanjut, yakni ruang kerja sempit sehingga menyulitkan bergeraknya tangan, dan panas lampu spiritus membuat kaca akuarium yang tipis menjadi pecah.

Idealnya, pekerjaan yang membutuhkan kondisi steril dilakukan di dalam Laminar Air Flow (LAF). Akan tetapi, harga LAF terlalu mahal dan tidak terjangkau untuk dibeli. Untuk mengatasi kontaminasi dari mikroorganisme yang tidak diinginkan, serta meningkatkan keberhasilan praktikum biologi pada materi mikrobiologi tanpa membeli LAF, sehingga keterampilan siswa dalam praktikum mikrorganisme dapat meningkat, disusun rumusan masalah sebagai berikut; Bagaimana modifikasi laminar sebagai alat pembelajaran biologi sma materi mikroorganisme?

Tujuan dari penulisan ini adalah untuk mendeskripsikan modifikasi laminar dalam menunjang kegiatan praktikum biologi terkait materi mikrobiologi maupun bioteknologi konvensional yang mengharuskan penggunaan kondisi aseptis dan steril sehingga meningkatkan keterampilan siswa dalam praktikum mikrorganisme.

Manfaat bagi guru setelah didapat pemecahan masalah ini adalah guru dapat mengajarkan bagaimana memperoleh kondisi aseptis untuk penuangan media, inokulasi mikroba seperti bakteri, jamur, potongan bagian tanaman seperti daun maupun batang untuk kultur jaringan dan meningkatkan keterampilan siswa dalam praktikum mikrorgsnisme.

Sedangkan manfaat bagi siswa meningkatnya keterampilan dalam praktikum mikrorgsnisme dan dapat mengetahui bentuk riil alat yang dipakai untuk melakukan aktivitas praktikum maupun penelitian dalam kondisi aseptik, Siswa dapat memanfaatkan alat untuk kegiatan praktikum mikrobiologi, dan siswa dapat memanfaatkan alat untuk kegiatan penelitian.

\section{Tinjauan Pustaka}

Kompetensi dasar yang mengacu pada Permendikbud nomor 37 tahun 2018, sebagaimana disajikan pada Tabel 1, memperlihatkan bahwa kelas $\mathrm{X}$ diharapkan dapat mempelajari materi tentang bakteri, di mana kegiatan praktikum bakteri membutuhkan alat dan bahan yang steril serta diterapkannya teknik aseptik. Begitu pula dengan kompetensi dasar 
pada kelas XII, peserta didik pada kelas ini diharapkan dapat melakukan percobaan bioteknologi konvensional seperti pembuatan yogurt, nata de coco, dan lainnya yang membutuhkan teknik aseptik dan kondisi steril. Oleh karena itu, keberadaan laminar menjadi penting dalam pembelajaran.

Salah satu faktor penting dalam keberhasilan praktikum mikroorganisme adalah ketersediaan alat dan bahan yang steril yang dilakukan dalam ruang kerja yang aseptis.

Tabel 1. Kompetensi dasar siswa SMA

(Permendikbud No. 37 Tahun 2018).

\begin{tabular}{cl}
\hline Kelas & \multicolumn{2}{c}{ Kompetensi Dasar } \\
& 3.5 Mengidentifikasi struktur, \\
cara hidup, reproduksi, dan \\
Kelas X \\
peran bakteri dalam kehidupan \\
4.5 Menyajikan data tentang ciri- \\
ciri dan peran bakteri dalam \\
kehidupan \\
3.10 Menganalisis prinsip- \\
prinsip Bioteknologi dan \\
penerapannya sebagai upaya \\
peningkatan kesejahteraan \\
manusia laporan hasil \\
4.10 Menyajikan laporan prinsip- \\
percobaan penerapan \\
prinsip bioteknologi \\
konvensional berdasarkan \\
scientific method.
\end{tabular}

Menurut Dya (2019), pengertian dari teknik aseptis adalah suatu sistem cara bekerja yang menjaga sterilitas ketika menangani pengkulturan mikroorganisme untuk mencegah kontaminasi terhadap kultur mikroorganisme yang diinginkan. Sterilisasi ada tiga macam, yang dapat dilakukan dengan dua cara, yakni secara manual oleh praktikan dengan sterilisasi secara kimiawi yang biasanya menggunakan senyawa desinfektan seperti alkohol, dan sterilisasi secara mekanik dan secara fisik dengan menggunakan suatu saringan yang berpori sangat kecil, pemanasan dan penyinaran yang berada dalam ruang kerja khusus.

Ruang kerja khusus yang memberikan suasana aseptis untuk praktikum mikroorganisme dikenal dengan nama Laminar Air Flow (LAF) Cabinet, atau Laminar. LAF Cabinet dapat meminimalkan resiko kegagalan akibat kontaminasi sampel dan memberikan rasa aman dan tingkat keselamatan pengguna dapat terjamin (Harjanto \& Raharjo, 2017).

Prinsip Laminar adalah dengan mengalirkan udara pada ruangan laboratorium ke dalam Laminar yang merupakan meja steril untuk melakukan kegiatan inokulasi mikroorganisme, yang dilengkapi dengan pre-filter dan HEPA (High Effeciency Particulate Air Filter) (Labnusantara, 2019). HEPA filter digunakan untuk menyaring udara agar diperoleh udara yang steril (Kruse et al., 1991).

Laminar yang banyak dijual memiliki prinsip kerja mekanik dan fisik dengan udara lebih dahulu disaring melalui pre-filter untuk mencegah masuknya partikel yang berukuran lebih dari $0,5 \mathrm{~mm}$, kemudian disaring lagi oleh saringan HEPA untuk mencegah masuknya partikel yang berukuran lebih dari $0,3 \mathrm{~mm}$, dan setelah itu dihisap oleh blower (Labnusantara, 2019). Selain itu Laminar juga dilengkapi dengan lampu yang menghasilkan sinar Ultraviolet (UV), yang berfungsi untuk menghilangkan pengotor serta mikroorganisme yang tidak diinginkan.

\section{Pembahasan}

Permasalahan yang peneliti alami setiap membimbing dan mendampingi siswa dalam praktikum yang terkait mikroorganisme adalah kontaminasi media maupun kultur, siswa rendah dalam keterampilan melakukan prosedur aseptik sehingga kontaminasi tinggi. Sehingga dengan segala upaya peneliti mencoba berbagai sarana dan prasarana untuk menurunkan kontaminasi dan meningkatkan keterampilan siswa dalam praktikum terkait mikroorganisme, seperti menggunakan akuarium yang dipesan khusus yang bisa digunakan untuk aktivitas pembuatan media maupun menginokulasi mikroorganisme. Namun penggunaan akuarium belum menyelesaikan permasalahan. Kemudian peneliti membuat desain laminar modifikasi yang tetap berprinsip meminimalkan kontaminasi, nyaman digunakan, dan berbiaya murah. Berikut ini adalah tahapan yang dilakukan oleh peneliti.

Tahap pertama, upaya membuat area kerja steril dalam praktikum telah dicoba dengan menggunakan akuarium kaca sebagaimana terlihat pada gambar 1. Sterilisasi yang dilakukan adalah dengan pemakaian alcohol di dalam ruang kaca. Metode ini ternyata tidak bisa menciptakan ruang kerja yang aseptis, sehingga masih terjadi kontaminasi pada hasil praktikum. Pada saat pengerjaan dilakukan, dialami kesulitan akibat ruang kerja yang sempit sehingga menyulitkan bergeraknya tangan. Bahan akuarium yang tipis mudah pecah saat terkena panas lampur spiritus. Dengan demikian metode ini tidak dapat digunakan lebih lanjut. Kegagalan ini sangat mungkin terjadi, karena menurut Harjanto dan Raharjo (2019) kegiatan yang melibatkan mikroorganisme memerlukan ruang steril seperti Laminar Air Flow. 


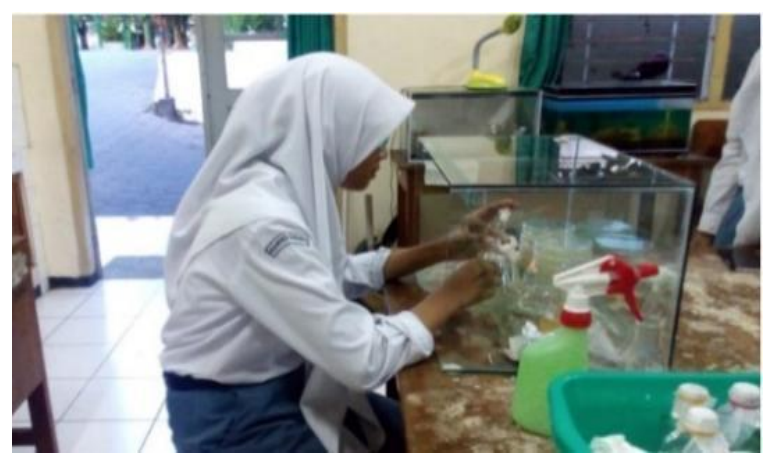

Gambar 1. Siswa bekerja dengan akuarium dalam praktikum.

Tahap kedua, dengan kegagalan metode pertama, maka kemudian dirancanglah laminar yang dapat memberikan sterilisasi secara mekanik dan fisik, yang selanjutnya disebut Laminar Modifikasi atau Lamodis. Untuk menghemat biaya, maka dilakukan modifikasi dengan rancangan sebagai berikut: 1) Tinggi ruang kerja Lamodis hanya $100 \mathrm{~cm}$, sedangkan LAF umumnya lebih dari $150 \mathrm{~cm}$. Dengan cara ini pemakaian sinar UV menjadi lebih efektif. 2) Udara ditekan oleh blower melalui saringan HEPA tanpa pre-filter, dan pintu belakang yang tertutup difungsikan sebagai pre-filter. Peletakan saringan HEPA setelah blower. Peletakan saringan HEPA setelah blower, dimaksudkan untuk memudahkan pemasangan saringan, memudahkan pembersihan saringan, dan kotoran yang menempel di blower dapat disaring. Sedangkan LAF umumnya memakai pre-filter sebelum melewati saringan HEPA. Dengan cara ini biaya material dapat dikurangi tanpa mengurangi kemampuan filtrasinya.
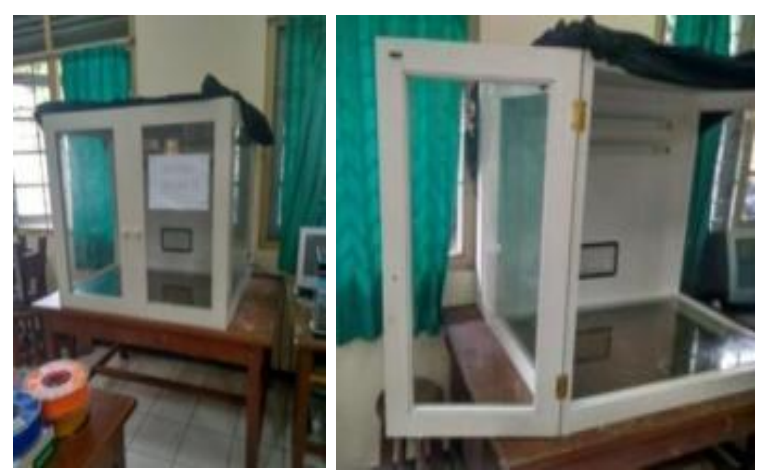

Gambar 2. Alat Lamodis tampak depan.

Hasil pembuatan Lamodis, dapat dilihat pada gambar 2 dan 3. Gambar 2 memperlihatkan Lamodis dari depan. Jendela dibuat terbuka ke samping. Jendela, dinding kiri-kanan-atas-bawah dibuat dengan kaca bening tebal, yang selain untuk menahan panas dan anti asam, juga untuk kemudahan melakukan pembersihan.
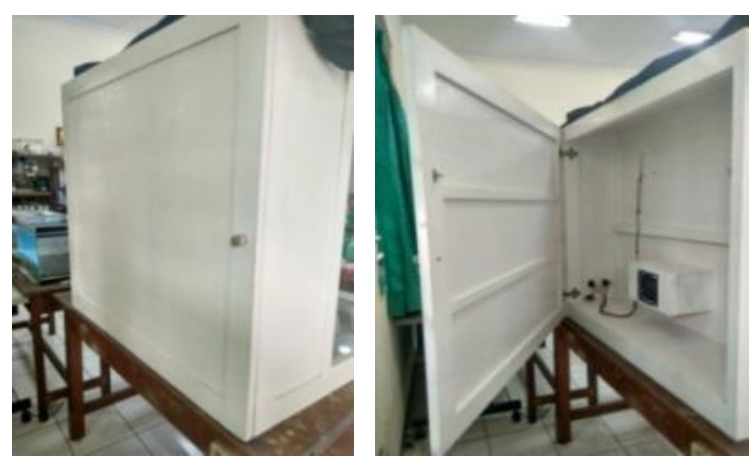

Gambar 3. Alat Lamodis tampak belakang.

Gambar 3 memperlihatkan adanya ruang tertutup yang di dalamnya berada kipas pendorong. Ruang tertutup tersebut dimaksudkan untuk menghindari debu dalam jumlah besar didorong oleh kipas.

Produksi alat ini sesuai dengan pendapat Harjanto dan Raharjo (2019) yang menyatakan bahwa faktor keberhasilan terjadinya ruang steril adalah pemakaian HEPA.

\section{Hasil Pemakaian Produk}

Penelitian oleh Harjanto dan Raharjo (2019) menunjukkan bahwa laminar mampu membantu memecahkan permasalahan dari mahasiswa yang sedang menyelesaikan penelitiannya dalam keberhasilan inokulasi atau penanaman mikroorganisme dengan menggunakan instrumen Laminar Air Flow. Penelitian tersebut mendukung penelitian peneliti terkait penggunaan lamodis dalam praktikum yang terkait mikrorganisme, dengan hasil peningkatan keterampilan dalam menerapkan kondisi aseptik ruangan kerja, alat, media, mengkulturkan mikroorganisme.

Pemakaian produk Lamodis dilakukan siswa saat praktikum yang terkait dengan mikrorganisme. Penggunaan oleh siswa pada tahun 2014 sampai 2018 dapat dilihat pada gambar 4.

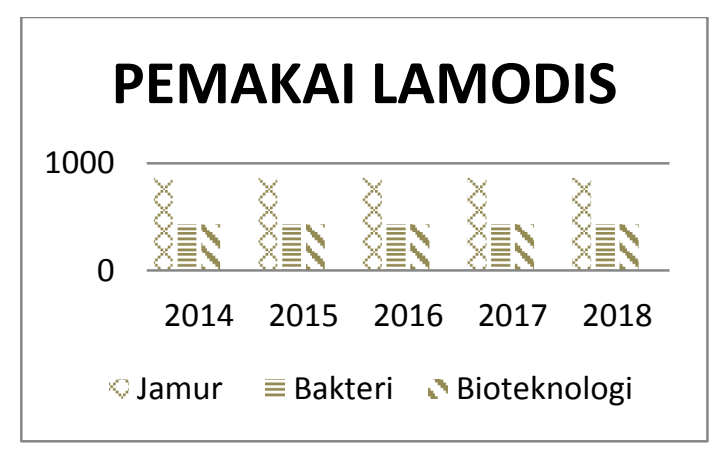

Gambar 4. Jumlah Siswa Pemakai Lamodis.

Penggunaan lamodis dalam kegitan praktikum materi jamur, bakteri dan bioteknologi adalah melakukan pembuatan media hingga 
inokulasi kultur mikrorganisme terjadwal rutin. Siswa bersemangat melakukan kegiatan tahapan langkah dalam menggunakan lamodis untuk materi terkait penggunaan mikrorganisme. Lamodis digunakan ketika menuang media untuk pertumbuhan bakteri ataupun jamur ke dalam beberapa petridish, kemudian media diamati apakah terdapat kontaminan setelah dilakukan penuangan. Pengamatan media yang telah dituang dilakukan setiap hari. Hasil uji coba Lamodis dapat dilihat pada Tabel 2, sedangkan contoh pemakaian Lamodis disajikan pada gambar 5 .

Tabel 2. Persentase media yang tidak terkontaminasi

\begin{tabular}{|c|c|c|}
\hline $\begin{array}{l}\text { Pembuatan } \\
\text { media ke - }\end{array}$ & $\begin{array}{r}\text { Persentas } \\
\text { terkor }\end{array}$ & $\begin{array}{l}\text { media tidak } \\
\text { aminasi }\end{array}$ \\
\hline & $\begin{array}{c}\text { Penuangan } \\
\text { di dalam } \\
\text { Lamodis }\end{array}$ & $\begin{array}{l}\text { Penuangan di } \\
\text { luar Lamodis }\end{array}$ \\
\hline 1 & 67 & 83 \\
\hline 2 & 100 & 75 \\
\hline Rata-rata & 83,5 & 79 \\
\hline
\end{tabular}

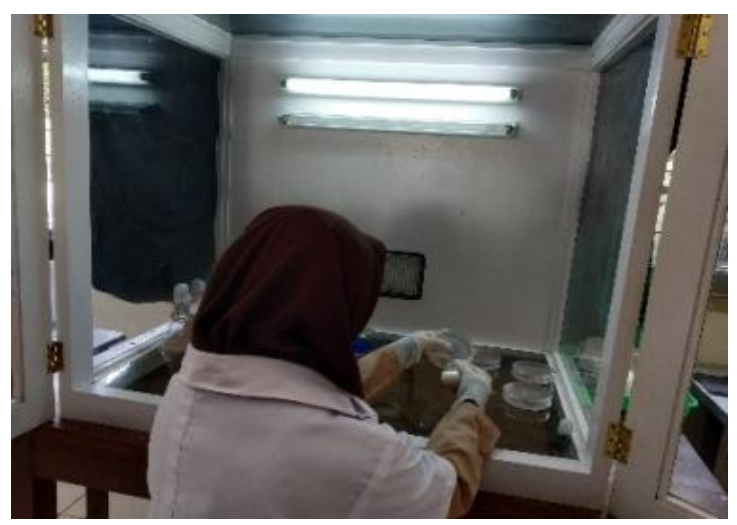

Gambar 5. Siswa memakai Lamodis dalam praktikum.

Berdasarkan data yang ada pada Tabel 2, penuangan media di dalam Lamodis mengurangi tingkat kontaminasi. Hal ini dapat dilihat dari persentase penuangan media yang tidak terkontaminasi di dalam Lamodis sebesar 83,5 \% dibandingkan dengan persentase penuangan media di luar Lamodis yang tidak terkontaminasi sebanyak $79 \%$.

Hasil tersebut menunjukkan efektivitas pemakaian Lamodis dibandingkan tanpa Lamodis yang dilakukan di meja kerja dengan hanya terlebih dahulu menyemprot meja dengan alkohol dan menempatkan lima lampu spiritus mengelilingi alat dan bahan yang akan digunakan menuangkan media kultur. Adapun contoh hasil penuangan ke media kultur yang terkontaminasi dan tidak terkontaminasi dapat dilihat pada Gambar 6.

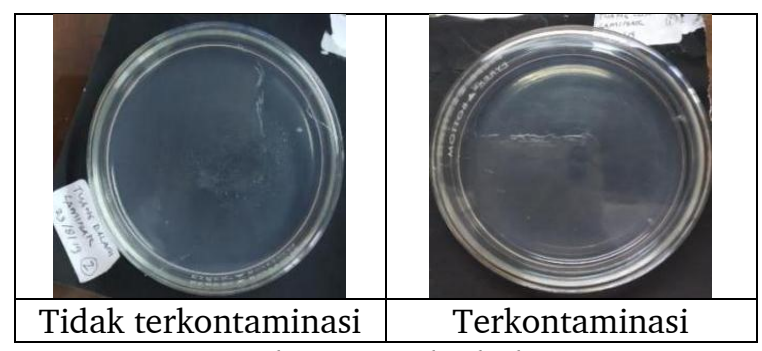

Gambar 6. Media kultur

Respon pengguna (siswa) atas efektivitas Lamodis dilakukan dengan penyebaran angket terbatas dengan sistem skala Likert dengan 4 pilihan, yakni Sangat Setuju (nilai 4), Setuju (nilai 3), Tidak Setuju (nilai 2), dan Sangat Tidak Setuju (nilai 1) dengan 10 (sepuluh) pernyataan persepsi. Adapun hasil angket 7 (tujuh) responden dapat dilihat pada Tabel 3.

Tabel 3. Persepsi siswa terhadap pemakaian Lamodis.

\begin{tabular}{|c|c|c|}
\hline No. & Pernyataan & Rerata \\
\hline 1 & $\begin{array}{l}\text { Ada prosedur kerja tertulis } \\
\text { pemakaian Lamodis. }\end{array}$ & 3,28 \\
\hline 2 & $\begin{array}{l}\text { Pemakaian Lamodis dilakukan } \\
\text { sebagaimana prosedur kerja } \\
\text { tertulis. }\end{array}$ & 3,28 \\
\hline 3 & Lampu UV berfungsi dengan baik. & 3,14 \\
\hline 4 & $\begin{array}{l}\text { Lampu penerangan berfungsi } \\
\text { dengan baik. }\end{array}$ & 3,57 \\
\hline 5 & $\begin{array}{l}\text { Kipas berfungsi dengan baik, yang } \\
\text { ditunjukkan dengan adanya angin } \\
\text { dari dinding di hadapan praktikan. }\end{array}$ & 3,28 \\
\hline 6 & $\begin{array}{l}\text { Sebelum praktikum dimulai, alat } \\
\text { alat yang terbuat dari kaca dalam } \\
\text { keadaan bersih. }\end{array}$ & 3,28 \\
\hline 7 & $\begin{array}{l}\text { Saat praktikum, udara steril tidak } \\
\text { mengganggu api bunsen. }\end{array}$ & 3,43 \\
\hline 8 & $\begin{array}{l}\text { Saat praktikum, kedua lengan } \\
\text { dapat bergerak bebas. }\end{array}$ & 3,71 \\
\hline 9 & $\begin{array}{l}\text { Saat praktikum, alat dan bahan } \\
\text { praktikum dapat dimasukkan ke } \\
\text { dalam Lamodis tanpa kesulitan. }\end{array}$ & 3,43 \\
\hline 10 & $\begin{array}{l}\text { Beberapa hari setelah praktikum, } \\
\text { media agar yang sudah diberi } \\
\text { mikroorganisme tertentu tidak } \\
\text { mengalami kontaminasi. }\end{array}$ & 2,71 \\
\hline Rerata & & 3,31 \\
\hline
\end{tabular}

Siswa memiliki persepsi bahwa Lamodis dapat memberikan sterilisasi secara fisik dan mekanik dengan nilai skala Likert 3,14 dan 3,28 dari nilai maksimal 4,00. Tabel 3 nomor 1, 2, 4, 6, 7, 8, dan 9 memperlihatkan bahwa Lamodis sudah berfungsi sebagaimana yang diharapkan yang ditunjukkan dengan nilai rerata yang tinggi. Nomor 3 memperlihatkan bahwa siswa memiliki persepsi berfungsinya lampu UV dengan baik, yang berarti Lamodis mampu melakukan sterilisasi secara fisik. Nomor 5 memperlihatkan 
bahwa siswa memiliki persepsi berfungsinya kipas dengan baik, yang mendorong udara dari luar ke dalam melalui filter HEPA, yang berarti Lamodis mampu melakukan sterilisasi secara mekanik. Nomor 10 menunjukkan bahwa persepsi siswa terhadap hasil akhir praktikum kurang baik. Mengingat bahwa Lamodis dipersiapkan untuk 2 (dua) macam sterilisasi, yakni sterilisasi fisik dan mekanik, dan keduanya telah berfungsi dengan baik; namun masih ada pertumbuhan organisme selain yang di inokulasikan. Kejadian ini kemungkinan besar disebabkan siswa baru mengenal dan melakukan praktikum dengan tingkat sterilisasi yang tinggi, sehingga masih mengalami kegagalan.

\section{PENINGKATAN KETERAMPILAN SISWA}

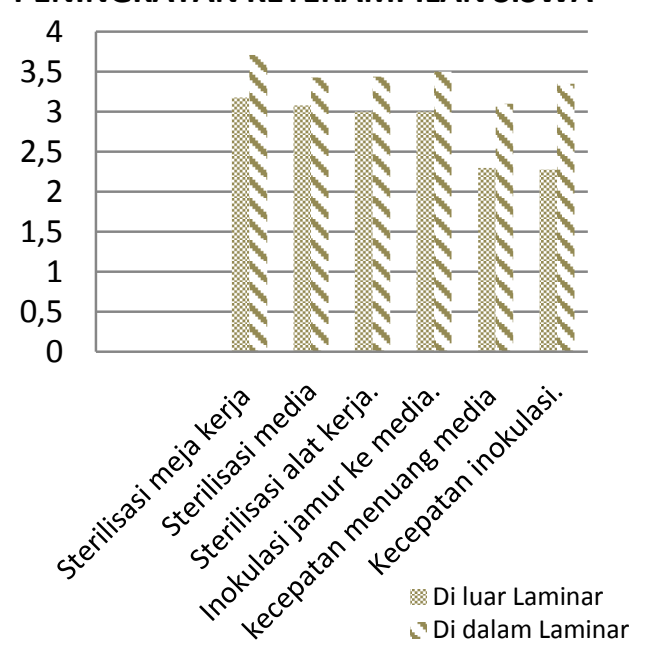

Gambar 7. Dinamika peningkatan keterampilan siswa melaksanakan praktikum menggunakan lamodis.

Gambar 7 menunjukkan bahwa penggunaan lamodis menimgkatkan keterampilan siswa dalam kemampuan melakukan sterilisasi meja kerja, media, alat-alat praktikum, inokulasi mikroorganisme. Hal tersebut di sebabkan saat bekerja di ruangan lamodis siswa lebih nyaman sehingga lebih konsentrasi dalam melakukan aktifitas praktikum. Penggunakan lamodis memberi nuansa baru yang memberi pengalaman nyata siswa dalam melakukan prosedur kerja secara aseptik, sehingga meningkatkan keterampilan siswa di setiap tahapan langkah.

\section{Simpulan dan Saran}

Lamodis dapat memberikan ruang kerja steril dengan harga lebih murah yang ditunjukkan dari hasil uji kontaminasi media menunjukkan bahwa uji di dalam Lamodis memiliki persentase tidak terkontaminasi sebesar $83,5 \%$, yang lebih baik daripada di luar Lamodis yang sebesar $79 \%$. Hasil rerata nilai angket terhadap siswa adalah 3,31 dari maksimal 4,00 yang menunjukkan bahwa Lamodis cukup baik digunakan untuk sterilisasi. Penggunaan lamodis meningkatkan keterampilan siswa dalam melakukan prosedur aseptik. Karenanya pembuatan Lamodis mendukung pembelajaran Biologi SMA yang terkait dengan mikroorganisme.

Walaupun Lamodis sudah teruji mampu memberikan ruang kerja steril, tetapi karena diletakkan di ruang laboratorium yang luas yang tidak dapat dikendalikan tingkat aseptiknya, maka hal ini juga berpotensi mendukung kegagalan praktikum. Oleh karena itu sebaiknya dibuatkan ruang khusus terbatas untuk mengoperasikan Lamodis.

\section{Daftar Pustaka}

Dya, S. Pengenalan alat, bekerja secara aseptik, sterilisasi alat dan medium, dan pembuatan media. Diunduh dari https://www.academia.edu/22311937/PE NGENALAN ALAT BEKERJA SECARA ASE PTIK STERILISASI_ALAT_DAN_MEDIUM DAN_PEMBUATAN MEDIA?auto $=$ downloa d, pada 16 Agustus 2019.

Harjanto, Sri dan Raharjo. (2017). Peran Laminar Air Flow Cabinet dalam Uji Mikroorganisme untuk Menunjang Keselamatan Kerja Mahasiswa di Laboratorium Mikrobiologi. Metana. Vol. 13(2):55-57.

Harjanto S., Raharjo. (2019). Peran Laminar Air Flow Cabinet Dalam Uji Mikroorganisme Bagi Mahasiswa Tugas Akhir Di Laboratorium Biokimia, Jurnal Pengelolaan Laboratorium Pendidikan, 1 (1) 2019, 1518, e-ISSN: 2654-251X

Kruse, Richard H., W. H. Pucket, dan J. H. Richardson. (1991). Biological Safety Cabinetry. Clinical Microbiology Reviews. Vol. 4, No.2: 207-241.

Labnusantara. (2019). Diakses dari https://labnusantara.co.id/laminar-airflow/pengertian-dan-prinsipkerja/\#targetText $=$ Prinsip\%20Laminar\%2 0Air\%20Flow\%20Cabinet,High\%20Effecien cy\%20Particulate\%20Air\%20Filter)., dilihat pada 16 Agustus 2019.

Permendikbud Nomor 37 Tahun 2018. Perubahan atas Peraturan Menteri Pendidikan dan Kebudayaan Nomor 24 Tahun 2016 tentang Kompetensi Inti dan Kompetensi Dasar Pelajaran pada Kurikulum 2013 pada Pendidikan Dasar dan Pendidikan Menengah. Diakses dari goeroendeso.files.wordpress.com/2019/01/ permendikbud-37-tahun-2018-tentang-kikd.pdf tanggal 15 September 2019. 